\title{
Study of the relationships between the health condition, caring in terms of health practice behavior on quality of life of parents of children with developmental disabilities
}

\author{
Bogja Jeoung \\ Department of Exercise Rehabilitation \& Welfare, College of Health Science, Gachon University, Incheon, Korea
}

This study aimed to determine the relationships between the quality of life, health condition, and caring in terms of health practice behaviors of parents of children with developmental disabilities. Two hundred forty-three parents of children with developmental disabilities participated. We examined the quality of life; the health practice behavior questionnaire comprised details of health condition, caring behavior, and diet, and it used a 10-point scale for scoring. The data were analyzed using a one-way analysis of variance; linear regression was conducted using IBM SPSS Statistics ver. 23.0. The results indicated that there were associations between quality of life, relations with family members, relations with neighbors, living standards, physical condition, and function among the subfactors. There were significant differences between ex- ercise practice behavior, quality of life, relations with family, relations with neighbors, living standards, physical condition and functioning, emotional state, and self-esteem among subfactors. It was found that there were significant differences between diet behavior and quality of life, and physical condition and function, emotional state in sub factor of quality of life. Based on the results of this study, if a health promotion behavior program is developed and applied systematically, it will contribute to improving the quality of life for parents' children with developmental disabilities.

Keywords: Developmental disability, Quality of life, Health promotion behavior

\section{INTRODUCTION}

According to the World Health Organization (WHO), quality of life (QoL) is defined as an individual's unique perspective of their position in life, and the degree of happiness that people experience in their daily lives (World Health Organization, 1994). In general, there are two types: objective and subjective. Objective QoL is measured via social factors such as income, education level, and health to objectively quantify and reflect people's objective circumstance within a given cultural context. In contrast, subjective QoL is defined as an individual's subjective satisfaction with their life, measured via the individual's mental sense of security including happiness, sense of stability, and intimacy (Diener and Suh, 1997; Diener et al., 1999).

The QoL of the parents of children with disabilities has been reported to be lower than that of the parents of children without disabilities (Dyson, 1991; Song and Singer, 2006). Particularly, the parents of children with developmental disabilities such as intellectual disability and autism are experiencing higher stress and have lower QoL than that of parents whose children have other types of disabilities (Cummings et al., 1966; Holroyd and McArthur, 1976).

This results from the fact that parents of children with developmental disabilities may experience marital conflict, parenting problems, emotional instability, and depression and that children with developmental disabilities are restricted from having opportunities to socialize with their neighbors or other family members due to emotional and behavioral problems and out-of-seat behavior; thus, such isolation can have a negative effect even on their siblings. The psychological response of parents of children with
${ }^{*}$ Corresponding author: Bogja Jeoung (iD https://orcid.org/0000-0002-7144-6179 Department of Exercise Rehabilitation \& Welfare, College of Health Science, Gachon University, 191 Hambangmoe-ro, Yeonsu-gu, Incheon 21936, Korea E-mail: bogja05@gachon.ac.kr

Received: November 2, 2019 / Accepted: December 9, 2019
This is an Open Access article distributed under the terms of the Creative Commons Attribution Non-Commercial License (http://creativecommons.org/licenses/by-nc/4.0/) which permits unrestricted non-commercial use, distribution, and reproduction in any medium, provided the original work is properly cited. 
developmental disabilities depends on various factors such as the personality, condition of current marriage, and social status; nonetheless, family tension and conflict will escalate in most cases if they fail to overcome feelings such as guilt regarding their children, desperation for recovery from disability, anger, and shame.

It is not an exaggeration to say that parents of children with developmental disabilities are the secondary victims, who themselves experience various difficulties in taking care of and raising their children. The burden of raising children with developmental disabilities inevitably leads to low QoL due to physical illness, weakness, loss of motivation for life, loss of satisfaction with life, and decline in well-being (George et al., 2011).

For people with developmental disabilities, parents and families are the most crucial supporters in life, and they greatly influence the development of the individual's character and behavior. In particular, parental mental health affects children's mental health (Solomon and Draine, 1995). Recent studies report that parents and families are experiencing high stress and more conflict due to children with disabilities, and their level of depression is high (Kazak and Marvin, 1984) and the lower the age of parents of children with disabilities, the more is the stress they experience and lower is the quality of their life. This is because the burden of the birth and upbringing of children with disabilities continues to be difficult to cope with for parents and families. Stress caused by children's disabilities adds on to the stress that already accumulates through critical events in life, generates psychological stress, which in turn leads to mental and physical health problems like depression, and ultimately damages the QoL. Moreover, parents of children with disabilities are reported to be less likely to improve their health for several reasons than are parents of children without disabilities (Yoong and Koritsas, 2012).

While traditional managerial method for healthy life would focus on hygiene to improve individual and group health and prevent diseases, it is reported that the higher the awareness, physical function, emotional function, and social function, the lower is the stress and depression (George et al., 2011) studies utilizing various types of moderating variables are being conducted in search of healthy ways to improve the QoL. In particular, leisure activities such as sports are reported to contribute to the improvement of stress and QoL. In addition, when there is a problem with the autonomic nervous system, a light exercise such as walking, bowling, jogging for about $20 \mathrm{~min}$ can enhance the QoL by preventing anxiety, depression, psychological contraction, stress and improving self-esteem, social skills, and communication (Roth and Cohen, 1986) In other words, regular exercise helps lower depres- sion, enhance the QoL, and improve physical function and vitality (Heesch et al., 2012). For middle-aged women, regular walking exercises more than 3 times a week contribute to improving mental health, stress, depression, and QoL.

George et al. (2011) reported that disproportionate nutrition management is not only associated with metabolism but can also lead to physical and psychological changes and that nutrition management, stress, and sleep are correlated (Heesch et al., 2012). As illustrated, regular exercise, continuous management of physical activities, leisure activities, nutrition management, etc. are essential as moderators of the relationships among mental health, depression, stress management, and improvement in QoL.

The role of parents is very important in their children's health care, including their health status, continuous and regular participation in exercise, and nutrition management (Boehm and Carter, 2019). Such parental care for their children's health will contribute accordingly to the betterment of the physical ability and improvement of children's health (Yoong and Koritsas, 2012), and it is assumed that the children's health improvement will contribute to the mental health of their parents, but prior studies mostly focus on the level of stress and QoL, rather than identifying the child's health care management as a variable moderating the improvement of the QoL of parents of children with developmental disabilities (Boehm and Carter, 2019; Burke and Hodapp, 2014; Cramm and Nieboer, 2012; Rodrigues et al., 2019; Yoong and Koritsas, 2012). Therefore, this study aimed to learn about how parental health management for children with developmental disabilities affects the QoL of the parents and contributes to the development of a healthy life for the parents.

\section{MATERIALS AND METHODS}

\section{Participants}

A total of 243 mothers of children with developmental disabilities, who lived in Incheon metropolitan, participated in this study. All potential participants received a comprehensive explanation of the proposed study. They were recruited through surveys and questionnaires distributed and collected with the help of the Association for Parents of Children with Developmental Disabilities, a health care center, and Incheon Sports Association for the Disabled. The participants were limited to the parents of the children who were diagnosed with intellectual disability, autism, Down syndrome, and developmental delay; parents of the children who were diagnosed with other types of accompanied developmental disabilities, such as learning disability or cerebral palsy, were excluded (Table 1). 


\section{Procedure}

The measurement instrument of the QoL for this study was consists of the following six subfactors: relationship with family (six items), relationship with neighbors (four items), living standard (11 items), physical condition and function (nine items), emotional state (nine items), and self-esteem (eight items), with 47 items in total. The measurement scale is a 5 -point scale, with scores ranging from one, "not at all" to five, "always," thus the higher the score, the higher the quality life.

The questionnaire used in this study included questions such as: "What do you think are the health conditions of your child with developmental disabilities?" in order to learn about the parents' perception on their children's health status; "Do you make your child with developmental disabilities exercise continuously

Table 1. Demographic of participants $(n=243)$

\begin{tabular}{lc}
\hline Variable & Value \\
\hline Parent's sex & \\
Father & $52(21.4)$ \\
Mother & $191(78.6)$ \\
Parent's age (yr) & $45.99 \pm 8.7(22-57)$ \\
Children's age (yr) & $65(26.7)$ \\
$3-6$ & $56(23.1)$ \\
$7-10$ & $16(6.6)$ \\
$11-14$ & $44(18.1)$ \\
$15-18$ & $62(25.5)$ \\
19-22 & \\
Parent's education & $99(40.8)$ \\
Under high school & $64(26.3)$ \\
Graduated college & $80(32.9)$ \\
Over graduated university & \\
Income (KRW/month) & $13(5.4)$ \\
Under 1,000,000 & $23(9.5)$ \\
1,000,000 to 2,000,000 & $61(25.1)$ \\
2,000,000 to 3,000,000 & $146(60.0)$ \\
Over 3,000,000 & \\
\hline
\end{tabular}

Values are presented as number (\%) or mean \pm standard deviation (range). KRW, Korean won. and regularly to improve their health?" in order to learn about their management for physical activities of their children; and "Do you continuously manage the nutrition of your child with developmental disabilities to improve his/her health?" in order to learn about their management for nutrition of their children, which is measured using a 10-point scale.

\section{Data analysis}

The IBM SPSS Statistics ver. 23.0 (IBM Co., Armonk, NY, USA) was used for data analysis. Descriptive statistics were used according to the study objectives, and Pearson and the Spearman rank correlation analyses were performed to examine the relationships between health behavior, stress, and QoL of parents of children with developmental disabilities. A linear regression was conducted on the stress and quality that showed a significant correlation to analyze their effects on health promotion behavior. The level of significance was set at $P<0.05$.

\section{RESULTS}

The mean score on QoL of parents of children with intellectual disability was $146.3 \pm 22.9$ (range, 82-219) (Table 1). There were correlations of health condition of their children with QoL $(r=0.174$, $P<0.01)$, relationship with family $(r=0.256, P<0.01)$, relationship with neighbors $(r=0.30, P<0.01)$, living standards $(r=0.132$, $P<0.05)$, and physical condition and function $(r=0.209, P<0.01)$ in QoL subitems (Table 2).

There were correlations of relationship with caring for exercise of children with QoL $(r=0.207, P<0.01)$, relationship with family $(r=0.199, P<0.01)$, relationship with neighbors $(r=0.192, P<$ $0.01)$, living standards $(r=0.144, P<0.05)$, physical condition and function $(r=0.132, P<0.05)$, emotional condition $(r=0.215$, $P<0.01)$, and self-esteem $(r=0.135 ; P<0.05)$. There were correlations of relationship with caring for diet of children and QoL $(r=$ $0.135, P<0.05)$, and physical condition and function $(r=0.126$, $P<0.05)$ and emotional condition $(r=0.151, P<0.05)$ in QoL su-

Table 2. Correlation between OoL, stress and health condition of children with developmental disabilities, health practice behavior of parents for health of children with developmental disabilities

\begin{tabular}{|c|c|c|c|c|c|c|c|}
\hline Variable & OoL & $\begin{array}{l}\text { Qol-sub relationship } \\
\text { with family }\end{array}$ & $\begin{array}{l}\text { Qol-sub relationship } \\
\text { with neighbors }\end{array}$ & $\begin{array}{l}\text { QoL-sub living } \\
\text { standard }\end{array}$ & $\begin{array}{l}\text { QoL-sub physical } \\
\text { condition and function }\end{array}$ & $\begin{array}{l}\text { QoL-sub emotional } \\
\text { condition }\end{array}$ & $\begin{array}{l}\text { Ool-sub } \\
\text { self-esteem }\end{array}$ \\
\hline Health condition of children & $0.173^{* *}$ & $0.256^{* *}$ & $0.300^{* *}$ & $0.132^{*}$ & $0.209^{* *}$ & 0.093 & 0.047 \\
\hline Caring for exercise of children & $0.207^{* *}$ & $0.199^{* *}$ & $0.192^{* *}$ & $0.144^{*}$ & $0.132^{*}$ & $0.215^{* *}$ & $0.135^{*}$ \\
\hline Caring for diet of children & $0.135^{*}$ & 0.050 & 0.084 & 0.121 & $0.126^{*}$ & $0.151^{*}$ & 0.090 \\
\hline
\end{tabular}

QoL, quality of life.

${ }^{*} P<0.05 .{ }^{* *} P<0.01$. 
bitems (Table 2).

The parents were aware of children's health condition and QoL, and subitems were analyzed using linear regression. The QoL score was predicted to increase to by $0.173(P<0.01)$ when the children's health condition score increases by 1 . The coefficient of determination that explained this change is $R^{2}=0.026$. The score on relationship with family in QoL was predicted to increase to by 0.256 $(P<0.001)$ when the children's health condition score increases by 1. The coefficient of determination that explains this change is $R^{2}=0.062$. The relationship with neighbors in QoL score was predicted to increase to by $0.30(P<0.001)$ when the children's health condition score increases by 1 . The coefficient of determination that explains this change is $R^{2}=0.086$. The score on living standards among QoL subitems was predicted to increase to by 0.132 $(P<0.05)$ when the children's health condition score increases by 1 . The coefficient of determination that explains this change is $R^{2}=$ 0.014 . The score on physical condition and function among QoL subitems was predicted to increase to by $0.209(P<0.001)$ when the children's health condition score increases by 1 . The coefficient of determination that explains this change is $R^{2}=0.04$ (Table 3).

The parents' caring for exercise behavior of children and QoL and its subitems were analyzed with linear regression. The QoL score was predicted to increase to by $0.207(P<0.001)$ when caring for exercise behavior of children score increase by 1 . The coefficient of determination that explains this change is $R^{2}=0.043$. The score on relationship with family among QoL subitems was predicted to increase to by $0.199(P<0.001)$ when caring for exercise behavior of children score increases by 1 . The coefficient of determination that explains this change is $R^{2}=0.040$ (Table 4).

The score on relationship with neighbors in QoL subitems was predicted to increase to by $0.193(P<0.01)$ when caring for exercise behavior of children score increase by 1 . The coefficient of determination that explains this change is $R^{2}=0.037$.

Table 3. Regression analysis of health condition of children with developmental disabilities and parent's quality of life ( $\mathrm{OLL})$

\begin{tabular}{lccccc}
\hline Variable & $\mathrm{b}$ & $\beta$ & $R^{2}$ & $T$ & $P$-value \\
\hline QoL-sub relationship with family & 0.164 & 0.256 & 0.062 & 4.250 & $0.000^{* * *}$ \\
QoL-sub relationship with neighbors & 0.317 & 0.300 & 0.086 & 5.030 & $0.000^{* * *}$ \\
$\begin{array}{l}\text { QoL-sub living standard } \\
\text { QoL-sub physical condition and }\end{array}$ & 0.046 & 0.132 & 0.014 & 2.110 & $0.035^{*}$ \\
function & 0.090 & 0.209 & 0.040 & 3.430 & $0.001^{* * *}$ \\
QoL-sub Emotional condition & 0.029 & 0.093 & 0.005 & 1.500 & 0.135 \\
QoL-sub self-esteem & 0.020 & 0.047 & -0.002 & 0.751 & 0.453 \\
QoL & 0.160 & 0.173 & 0.026 & 2.760 & $0.006^{* *}$ \\
\hline
\end{tabular}

${ }^{*} P<0.05$. ${ }^{* *} P<0.01$. ${ }^{* *} P<0.001$.
The score on living standard in QoL item was predicted to increase to by $0.144(P<0.05)$ when caring for exercise behavior of children score increases by 1 . The coefficient of determination that explains this change is $R^{2}=0.021$.

The score on emotional condition in $\mathrm{QoL}$ item was predicted to increase to by $0.215(P<0.001)$ when caring for exercise behavior of children score increases by 1 . The coefficient of determination that explains this change is $R^{2}=0.046$. The score on self-esteem among QoL subitems was predicted to increase to by $0.135(P<$ 0.05 ) when caring for exercise behavior of children score increases by 1 . The coefficient of determination that explains this change is $R^{2}=0.018$.

The score on relationship with family among QoL subitems was predicted to increase to by $0.321(P<0.001)$ when interpersonal support in health-promoting life style profile score increases by 1 . The coefficient of determination that explains this change is $R^{2}=$ 0.100 . The score on relationship with family in QoL subitems was predicted to increase to by $0.327(P<0.001)$ when stress management in health-promoting lifestyle profile score increases by 1 . The coefficient of determination that explains this change is $R^{2}=0.103$ (Table 4).

The parents' caring for diet behavior of children and QoL and its subitems were analyzed with linear regression results. The $\mathrm{QoL}$ score was predicted to increase to by $0.135(P<0.05)$ when caring for diet behavior of children score increases by 1 . The coefficient of determination that explains this change is $R^{2}=0.018$ (Table 5).

The physical condition and function in QoL subitems score were predicted to increase to by $0.126(P<0.05)$ when caring for diet behavior of children score increases by 1 . The coefficient of determination that explains this change is $R^{2}=0.016$. The emotional condition in QoL item score was predicted to increase to by 0.151 $(P<0.05)$ when caring for diet behavior of children score increases by 1 . The coefficient of determination that explains this change is

Table 4. Regression analysis of exercise caring of children with developmental disabilities and parent's quality of life (OoL)

\begin{tabular}{lccccl}
\hline Variable & $\mathrm{b}$ & $\beta$ & $R^{2}$ & $T$ & $P$-value \\
\hline OoL-sub relationship with family & 0.149 & 0.199 & 0.040 & 3.283 & $0.001^{* * *}$ \\
QoL-sub relationship with neighbors & 0.236 & 0.193 & 0.037 & 3.145 & $0.002^{* *}$ \\
$\begin{array}{l}\text { OoL-sub living standard } \\
\text { OoL-sub physical condition and }\end{array}$ & 0.058 & 0.144 & 0.021 & 2.316 & $0.021^{*}$ \\
$\quad$ & 0.066 & 0.132 & 0.017 & 2.145 & $0.033^{*}$ \\
function & & & & & \\
QoL-sub emotional condition & 0.077 & 0.215 & 0.046 & 3.351 & $0.000^{* * *}$ \\
OoL-sub self-esteem & 0.068 & 0.135 & 0.018 & 2.197 & $0.029^{*}$ \\
OoL & 0.022 & 0.207 & 0.043 & 3.350 & $0.001^{* * *}$ \\
\hline
\end{tabular}

${ }^{*} P<0.05 .{ }^{*} P<0.01 .{ }^{* *} P<0.001$. 
Table 5. Regression analysis of caring for diet of children with developmental disabilities and parent's quality of life ( $\mathrm{OoL})$

\begin{tabular}{lccccc}
\hline Variable & $\mathrm{b}$ & $\beta$ & $R^{2}$ & $\mathrm{~T}$ & $P$-value \\
\hline OoL-sub relationship with family & 0.031 & 0.050 & 0.002 & 0.805 & 0.422 \\
OoL-sub relationship with neighbors & 0.085 & 0.084 & 0.007 & 1.365 & 0.173 \\
OoL-sub living standard & 0.400 & 0.121 & 0.015 & 1.941 & 0.053 \\
$\begin{array}{l}\text { OoL-sub physical condition and } \\
\text { function }\end{array}$ & 0.052 & 0.126 & 0.016 & 2.05 & $0.041^{*}$ \\
OoL-sub emotional condition & 0.045 & 0.151 & 0.023 & 2.469 & $0.014^{*}$ \\
OoL-sub self-esteem & 0.038 & 0.090 & 0.008 & 1.468 & 0.143 \\
OoL & 0.012 & 0.135 & 0.018 & 2.156 & $0.032^{*}$ \\
\hline
\end{tabular}

${ }^{*} P<0.05$.

$R^{2}=0.023($ Table 5)

\section{DISCUSSION}

This study analyzed how parents' caring for health of children affects the parents' QoL and concluded that perceived health of their children was correlated with their QoL and the better the health status of the children were, the better was the parents' QoL. In addition, caring for exercise behavior and diet behavior to improve children's health correlated with the parents' QoL and they mutually affected one another. The health status of the child with developmental disabilities was positively correlated with the subfactors of QoL (relationship with family, relationship with neighbors, living standards, and physical condition and function). The higher the score for caring for exercise behavior of children, the more positive the results were in all six subfactors of $\mathrm{QoL}$ (relationship with family, relationships with neighbors, living standards, physical condition and function, emotional state, and self-esteem). The findings also showed that the higher the score for caring for diet behavior of children, the more positive the results were in the subfactors (physical condition and function, emotional state). Similar result has been proposed in George et al. (2011), study in which the caring condition (caring for exercise and diet behavior of their children) of parents of children with cerebral palsy affected the parents' stress and depression (Burke and Hodapp, 2014; Walker et al., 1987; Yoong and Koritsas, 2012). Therefore, it would be safe to say that parents of children with developmental disabilities contribute to their own QoL when they care for exercise and diet behavior of their child to improve their health. By enhancing their children's health via caring for exercise and diet behavior of their child, the stress level of the parents' drops and their QoL improves. Moreover, in a study conducted with middle-aged women, showed how engaging in sports activities contribute to the betterment of the QoL. Continuous participation in exercise elevates your awareness on health and alleviates stress (Heesch et al., 2012; Walker et al., 1987). If a systematic and practical health improvement program is developed and implemented for the parents of the children with developmental disabilities based on the findings of this study and the prior ones, it will hugely contribute to the alleviation of their stress and enhancement of their QoL.

\section{CONFLICT OF INTEREST}

No potential conflict of interest relevant to this article was reported.

\section{REFERENCES}

Boehm TL, Carter EW. Family quality of life and its correlates among parents of children and adults with intellectual disability. Am J Intellect Dev Disabil 2019;124:99-115.

Burke MM, Hodapp RM. Relating stress of mothers of children with developmental disabilities to family-school partnerships. Intellect Dev Disabil 2014;52:13-23.

Cramm JM, Nieboer AP. Longitudinal study of parents' impact on quality of life of children and young adults with intellectual disabilities. J Appl Res Intellect Disabil 2012;25:20-28.

Cummings ST, Bayley HC, Rie HE. Effects of the child's deficiency on the mother: a study of mothers of mentally retarded, chronically ill and neurotic children. Am J Orthopsychiatry 1966;36:595-608.

Diener E, Suh E. Measuring quality of life: economic, social, and subjective indicators. Soc Indicat Res1997;40:189-216.

Diener E, Suh E, Lucas E, Smith H. Subjective well-being: three decades of progress. Psychol Bull 1999;125:276-302.

Dyson LL. Families of young children with handicaps: parental stress and family functioning. Am J Ment Retard 1991;95:623-629.

George VA, Shacter SD, Johnson PM. BMI and attitudes and beliefs about physical activity and nutrition of parents of adolescents with intellectual disabilities. J Intellect Disabil Res 2011;55:1054-1063.

Heesch KC, van Uffelen JG, van Gellecum YR, Brown WJ. Dose-response relationships between physical activity, walking and health-related quality of life in mid-age and older women. J Epidemiol Community Health 2012;66:670-677.

Holroyd J, McArthur D. Mental retardation and stress on the parents: a contrast between Down's syndrome and childhood autism. Am J Ment Defic 1976;80:431-436.

Kazak AE, Marvin RS. Differences, difficulties and adaption: stress and social networks in families a handicapped child. Fam Relat 1984;33: 
67-77.

Rodrigues SA, Fontanella BJB, de Avó LRS, Germano CMR, Melo DG. A qualitative study about quality of life in Brazilian families with children who have severe or profound intellectual disability. J Appl Res Intellect Disabil 2019;32:413-426.

Roth S, Cohen LJ. Approach, avoidance, and coping with stress. Am Psychol 1986;41:813-819.

Solomon P, Draine J. Adaptive coping among family members of persons with serious mental illness. Psychiatr Serv 1995;46:1156-1160.

Song L, Singer M. Life stress, social support, coping and depressive symp- toms: a comparison netween the general population and family caregivers. Int J Soc Welf 2006;15:172-180.

Yoong A, Koritsas S. The impact of caring for adults with intellectual disability on the quality of life of parents. J Intellect Disabil Res 2012;56: 609-619.

Walker SN, Sechrist KR, Pender NJ. The health-promoting lifestyle profile: development and psychometric characteristics. Nurs Res 1987;36: 76-81.

World Health Organization. WHOQoL study protocol (MNH/PSF/93-9). Geneva (Switzerland): World Health Organization; 1994. 